\title{
Elevated aspartate aminotransferase and monocyte counts predict unfavorable prognosis in patients with malignant pleural mesothelioma
}

\author{
A. ZHANG ${ }^{\ddagger}$, S. CAO ${ }^{\ddagger}$, S. JIN, J. CAO, J. SHEN, B. PAN, R. ZHU, Y. YU* \\ Department of Medical Oncology, Harbin Medical University Cancer Hospital, Harbin, China. \\ *Correspondence: yuyan@ems.hrbmu.edu.cn \\ ${ }^{*}$ Contributed equally to this work.
}

Received June 18, 2016 / Accepted August 21, 2016

\begin{abstract}
Limited biomarkers predicting prognosis of malignant pleural mesothelioma (MPM) have been identified. The present study aims to assess potential laboratory prognostic factors of MPM. We retrospectively reviewed the clinical data of 105 patients with MPM. The overall survival and prognostic factors were assessed by Kaplan-Meier curves and Cox regression analysis. A receiver operating characteristic (ROC) curve analysis was performed to determine the optimal cut-off values. The mean age of the 105 patients ( $62 \mathrm{men}, 43$ women) was 56.0 years. The major clinical presentations were dyspnea, cough and chest pain. The most common laboratory abnormalities were thrombocytosis and elevated monocyte count. Significant prognostic factors on univariate analysis were performance status (PS), serum albumin, aspartate aminotransferase (AST), lactate dehydrogenase (LDH), alkaline phosphatase (ALP), monocyte, platelet to lymphocyte ratio (PLR), lymphocyte to monocyte ratio (LMR) and treatment strategy. Multivariate analysis showed PS, AST, monocyte, and treatment strategy were statistically significant $(p<0.05)$. Higher AST level and monocyte count were both related to the presence of anemia ( $p=0.001$ and 0.010 , respectively) and higher ALP level ( $p=0.049$ and 0.001 , respectively). A higher AST level was also associated with higher alanine aminotransferase (ALT) and LDH level $(p<0.05)$. A higher monocyte count was also correlated with male patients, higher white blood cell (WBC), platelet, neutrophil counts, lower red blood cell (RBC) and LMR counts $(p<0.05)$. In conclusion, our data show that PS $<2$, normal AST level, lower monocyte count, and multimodality treatment are independent positive prognostic factors of MPM. The elevated AST and monocyte levels represent unfavorable prognostic biomarkers of MPM.
\end{abstract}

Key words: malignant pleural mesothelioma, prognostic analysis, inflammation, aspartate aminotransferase, monocyte

Malignant pleural mesothelioma (MPM) is a lethal disease with an increasing incidence worldwide [1,2]. Approximately $80 \%$ of all mesothelioma cases have a pleural origin [3]. MPM remains a public health issue and will cause massive economic burdens in the following decades due to the previous widespread use of asbestos materials and the long latency between asbestos exposure and disease onset [4]. MPM has insidious characteristics and the median duration of symptoms is 6 months [5]. The final diagnosis is usually made in an advanced stage due to its non-specific clinical presentations and noncontributory radiological features.

MPM is also a treatment-resistant disease, and there is currently no established uniform treatment strategy. The median overall patient survival is 9-17 months regardless of stage [2]. The recommended therapeutic option in selected cases is multimodality treatment consisting of surgery followed by chemo- and/or radiotherapy. This therapeutic approach is associated decreased local recurrences and increased survival $[3,6]$. However, the majority of patients are inoperable at diagnosis. Thus, the treatment options include chemo-, radio-, immunotherapy or best supportive care.

Serum biomarkers have an important role in the differential diagnosis and in predicting MPM prognosis. However, there are limited serum biomarkers identified at present [1]. Patients receive routine blood tests, liver function evaluations, and tumor marker analyses at hospital admission. Serum biochemical markers are readily available and the identifying of serum biomarkers is critical for improving clinical practice. These serum markers are rarely taken into consideration at the same time and the majority studies focus on the single role of 
routine blood tests or markers of liver function evaluations $[5,6]$. Our study aims to simultaneously analyze these markers and assess the potential prognostic values of laboratory examinations in patients with MPM.

\section{Patients and methods}

Patients. We conducted a retrospective analysis on 105 cases with pathologically confirmed MPM who were registered and followed up in our hospital between April 2007 and November 2013. Our study was approved by the Ethics Committee of Harbin Medical University Cancer Hospital and written informed consent was obtained from each patient. The laboratory, clinical, and radiographic variables were defined as potential prognostic factors and were measured at the time of diagnosis.

The following pretreatment parameters were evaluated for prognostic impact: age ( $\leq 56$ or $>56$ years), gender, PS (performance status, ECOG scale), the presence of pleural effusion, tumor location (right or left), serum red blood cell (RBC), platelet $(\leq 300,000$ or $>300,000 / \mu l)$, white blood cell (WBC, $\leq 10$ or $\left.>10 \times 10^{9} / \mathrm{L}\right)$, hemoglobin, neutrophil $(\leq 5.89$ or $\left.>5.89 \times 10^{9} / \mathrm{L}\right)$, lymphocyte $\left(\leq 1.265\right.$ or $\left.>1.265 \times 10^{9} / \mathrm{L}\right)$, monocyte $\left(\leq 0.545\right.$ or $>0.545 \times 10^{9} / \mathrm{L}$ ), NLR (neutrophil to lymphocyte ratio, $\leq 4.5$ or $>4.5$ ), PLR (platelet to lymphocyte ratio, $\leq 155.45$ or $>155.45$ ), LMR (lymphocyte to monocyte ratio, $\leq 2.36$ or $>2.36$ ), aspartate aminotransferase (AST, $\leq 40$ or $>40 \mathrm{U} / \mathrm{L}$ ), alanine aminotransferase (ALT, $\leq 40$ or $>40 \mathrm{U} / \mathrm{L}$ ), lactate dehydrogenase (LDH, $\leq 183.5$ or $>183.5 \mathrm{U} / \mathrm{L}$ ), alkaline phosphatase (ALP, $\leq 96.5$ or $>96.5 \mathrm{U} / \mathrm{L}$ ), total protein $(\leq 64$ or $>64 \mathrm{~g} / \mathrm{L})$, albumin level $(\leq 40$ or $>40 \mathrm{~g} / \mathrm{L})$, globulin $(\leq 35$ or $>35 \mathrm{~g} / \mathrm{L})$, glucose $(\leq 6.1$ or $>6.1 \mathrm{mmol} / \mathrm{L})$, total bilirubin $(\leq 19$ or $>19 \mu \mathrm{mol} / \mathrm{L}), \gamma$-glutamyl transferase $(\gamma$-GGT, $\leq 54$ or $>54 \mathrm{U} / \mathrm{L}$ ), carcinoembryonic antigen (CEA, $\leq 5$ or $>5 \mathrm{ng} \mathrm{ml}$ ), squamous cell carcinoma antigen (SCC, $\leq 1.5$ or $>1.5 \mathrm{ng} / \mathrm{ml}$ ), neuron specific enolase (NSE, $\leq 15$ or $>15 \mathrm{ng} / \mathrm{ml}$ ), cancer antigen 125 (CA125, $\leq 35$ or $>35 \mathrm{U} / \mathrm{ml}$ ) and different treatment strategies. A low serum RBC level was defined as a red blood cell count $<3.5$ or $4.0 \times 10^{9} / \mathrm{L}$ in females and males, respectively. Anemia is defined as a hemoglobin value $<12 \mathrm{~g} / \mathrm{dl}$ in men and $11 \mathrm{~g} / \mathrm{dl}$ in women. Thrombocytosis was defined with a platelet count $>300,000 / \mathrm{mm}^{3}$. The NLR, PLR, and LMR values were calculated using the neutrophil, platelet, lymphocyte and monocyte counts as the ratio of neutrophil and platelet counts to lymphocytes or lymphocyte to monocyte counts, respectively.

Statistical analysis. A receiver operating characteristic (ROC) curve analysis was used to calculate the optimal cutoff point for neutrophil, lymphocyte, monocyte, LDH, ALP, NLR, PLR, and LMR. The relationships between the AST, monocyte and the clinico-pathological features were evaluated using the chi-squared test. The survival curves and $95 \%$ confidence intervals (CIs) were obtained using the KaplanMeier method, and the survival was compared by log-rank test. The overall survival time was defined from diagnosis to death. If the patients were still alive, then the survival was defined from the period of final diagnosis to the last follow-up of November 2013. A univariate analysis was used to examine the prognostic importance of all factors. The prognostic factors with $P$-value $<0.05$ in the univariate analysis were examined in the multivariate analysis. SPSS 20.0 statistical software was used for statistical analysis. All $P$-values $<0.05$ were considered statistically significant.

\section{Results}

Patient characteristics. This study included 105 patients (62 men, 43 women). The mean age was 56.0 years (range $18-77)$. The PS was $\geq 2$ points in 6 cases (5.7\%) and less than 2 points in 99 cases $(94.3 \%)$. The median time from initial symptoms presented to diagnosis was 2.0 months. The median survival time (MST) was 20.0 months and 2 patients survived more than 60 months (Figure 1). The survival rates at 1-, 2and 5 -years were $68.2 \%, 40.8 \%$ and $13.8 \%$, respectively. The most common symptoms at patient presentation were dyspnea $(69 / 105,65.7 \%)$, cough $(53 / 105,50.5 \%)$, chest pain $(52 / 105$, $49.5 \%)$ and weight loss $(27 / 105,25.7 \%)$. The diagnostic protocols used included open pleural biopsy in 38 patients (36.2\%) and closed pleural biopsy in 50 patients (47.6\%). Cytological examinations (cytological analysis and sediment embedding) were positive in 17 patients (16.2\%). Details are presented in Table 1.

Laboratory examinations. Routine blood test and liver function test were performed in all 105 patients. The most common patient abnormalities included the following: thrombocytosis (59/105, 56.2\%), elevated monocyte count (55/105, $52.4 \%)$, low serum albumin level (49/105, 46.7\%), high r-GGT $(42 / 105,40.9 \%)$, ALT $(31 / 105,29.5 \%)$, globulin $(29 / 105$,

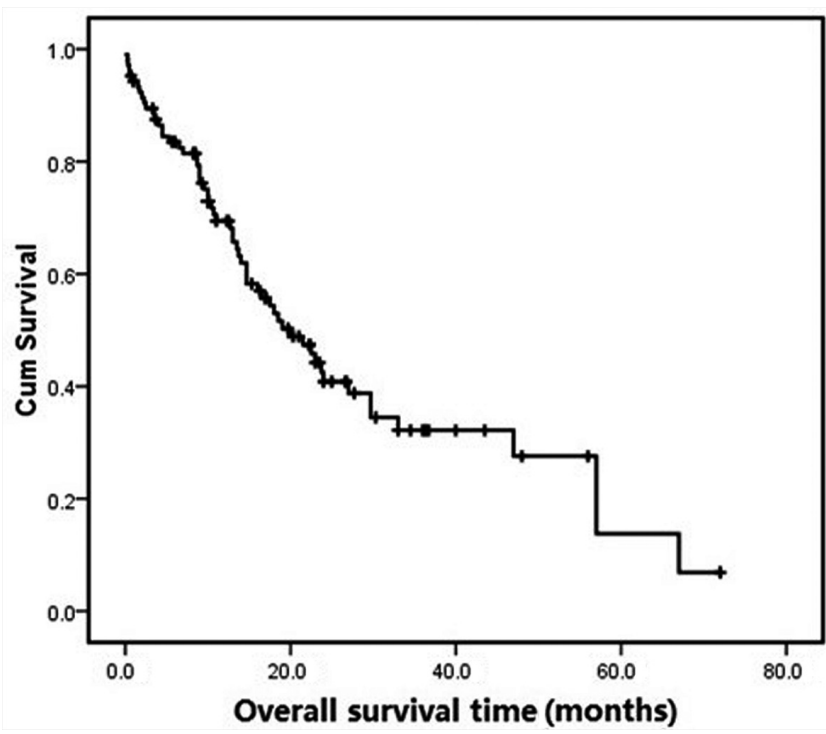

Figure 1. Overall survival from the time of diagnosis for the whole series. 
Table 1. Clinical characteristics of patients with MPM

\begin{tabular}{lcc}
\hline Features & $\mathrm{n}$ & $\%$ \\
\hline Age (years) & 53 & 50.5 \\
$\quad \leq 56$ & 52 & 49.5 \\
$\quad>56$ & & \\
Gender & 62 & 59.1 \\
$\quad$ Male & 43 & 40.9 \\
Female & & \\
Symptoms initially presented & 69 & 65.7 \\
Dyspnea & 53 & 50.5 \\
Cough & 52 & 49.5 \\
$\quad$ Chest pain & 27 & 25.7 \\
Weight loss & & \\
PS (performance status, ECOG) & 99 & 94.3 \\
0-1 & 6 & 5.7 \\
2 & & \\
Diagnostic protocols & 38 & 36.2 \\
Open pleural biopsy & 50 & 47.6 \\
Closed pleural biopsy & 17 & 16.2 \\
Cytological examination & & \\
Treatment strategies & 15 & 14.3 \\
Best supportive care group (BSC) & 82 & 78.1 \\
Non-surgical group & 8 & 7.6 \\
Surgical group & & \\
\hline
\end{tabular}

Non-surgical group consists of the single or combined treatment of chemo-, radio- or immuno- or target therapy. Surgical group consists of the treatment of surgery and adjuvant therapies (chemo-, radio- or immunotherapy).

27.6\%), LDH $(20 / 105,19.1 \%)$ and anemia (19/105, 18.1\%). There were elevated tumor markers such as CEA, CA125, SCC, and NSE observed in 6.6\% (5/76), 66.7\% (22/33), 5.7\% (2/35) and $43.2 \%(16 / 37)$ of patients, respectively.

Patient management. There were $15(14.3 \%)$ patients treated with best supportive care, $82(78.1 \%)$ with the single or combined treatment of chemo-, radio-, immuno- or targeted therapy, and 8 (7.6\%) with surgery plus adjuvant therapies (chemo- and/or radiotherapy). Within the $82 \mathrm{pa}$ tients, 67 patients $(81.7 \%)$ were treated with pemetrexed and platinum-based chemotherapy, 8 (9.8\%) with gemcitabine or vinorelbine and platinum-based chemotherapy, 4 (4.9\%) with single pemetrexed based chemotherapy, and the rest 3 (3.6\%) received radio-, immuno- or targeted therapy (bevacizumab). The median survival time for all cases was 20.0 months (95\% CI 13.947-26.053): 2.3, 22.5 and 29.7 for patients treated with best supportive care, adjuvant chemoradiotherapy and surgery plus adjuvant therapies, respectively.

The cutoff values for neutrophils, lymphocytes, monocytes, LDH, ALP, NLR, PLR, and LMR. The mean $( \pm S D$, Standart Deviation) neutrophil, lymphocyte and monocyte counts were $5.88( \pm 2.86), 1.74( \pm 0.62), 0.61( \pm 0.31) \times 10^{9} / \mathrm{L}$, respectively. The ROC analysis showed the optimal monocyte cut-off value was 0.545 ( $p=0.034$, AUC, $0.621 ; 95 \%$ CI, $0.512-0.730$ ) for overall survival. The patients were then divided into two groups: high monocyte $\left(>0.545 \times 10^{9} / \mathrm{L}\right)$ and low monocyte group $\left(\leq 0.545 \times 10^{9} / \mathrm{L}\right)$. There were $55(52.4 \%)$ patients in the high monocyte group and 50 (47.6\%) patients in the low monocyte group. The neutrophil of 5.89 ( $p=0.043$, AUC, $0.616 ; 95 \%$ CI, 0.507-0.724), lymphocyte of 1.265 ( $p=0.022$, AUC, $0.631 ; 95 \%$ CI, $0.525-0.736$ ), LDH of 183.5 U/L ( $p=0.799$, AUC, $0.515 ; 95 \%$ CI, $0.404-0.625)$, ALP of 96.5 U/L ( $p=0.003$, AUC, $0.667 ; 95 \%$ CI, $0.563-0.771$ ), NLR of 4.5 ( $p=0.001$, AUC, $0.697 ; 95 \%$ CI, 0.597-0.798), PLR of 155.45 $(p=0.002$, AUC, $0.680 ; 95 \%$ CI, $0.577-0.784)$ and LMR of 2.36 ( $p=0.001$, AUC, $0.695 ; 95 \%$ CI, $0.594-0.797$ ) were selected as the optimal cut-off values.

Univariate analysis. Each pretreatment prognostic factor was assessed by univariate analysis. The univariate analysis results showed the following were significant prognostic factors: PS ( $p<0.001)$, serum albumin $(p=0.029)$, AST ( $p=0.004)$, LDH $(p=0.016)$, ALP $(p=0.025)$, monocyte count $(p=0.001)$, PLR $(p=0.046)$, LMR $(p<0.001)$ and treatment strategy $(p=0.002)$. The role of NLR was not assessed because more than $50 \%$ patients were still alive in the high NLR group. We also analyzed the roles of CEA, CA125, SCC, and NSE by univariate analysis. The results revealed that high CEA level $(\mathrm{n}=76,8.7$ vs. 23.0 months, $p<0.001)$ and SCC $(\mathrm{n}=35,2.9$ vs. 25.5 months, $p<0.001$ ) were associated with poor MPM prognosis. However, there was no statistical difference for CA125 $(\mathrm{n}=33, p=0.307)$ and NSE $(\mathrm{n}=37, p=0.101)$. The data showed the following factors were correlated with a poor prognosis: $\mathrm{PS} \geq 2$ points, serum albumin $\leq 40 \mathrm{~g} / \mathrm{L}, \mathrm{AST}>40 \mathrm{U} / \mathrm{L}$, $\mathrm{LDH}>183.5 \mathrm{U} / \mathrm{L}, \mathrm{ALP}>96.5 \mathrm{U} / \mathrm{L}$, monocyte $>0.545 \times 10^{9} / \mathrm{L}$, $\mathrm{PLR}>155.45, \mathrm{LMR} \leq 2.36, \mathrm{CEA}>5 \mathrm{ng} / \mathrm{ml}, \mathrm{SCC}>1.5 \mathrm{ng} / \mathrm{ml}$ and best supportive care (Table 2). The variables examined in the final multivariate analysis were PS, serum albumin, AST, LDH, ALP, monocyte, PLR, LMR, and treatment strategy.

Multivariate analysis. The multivariate analysis showed PS $(p<0.001)$, AST $(p=0.031)$, monocyte count $(p=0.012)$ and treatment strategy $(p=0.007)$ were statistically significant (Table 3). The hazard ratios of death were observed for PS $\geq 2$ points ( 6.178 fold increase compared to $P S<2$ points), monocyte $>0.545 \times 10^{9} / \mathrm{L}$ ( 2.666 fold increase compared to monocyte $\left.\leq 0.545 \times 10^{9} / \mathrm{L}\right)$ and AST $>40 \mathrm{U} / \mathrm{L}$ ( 2.439 fold increase compared to patients with AST level $\leq 40 \mathrm{U} / \mathrm{L})$. The factors $\mathrm{PS}<2$ points, normal AST level, low monocyte count, and multimodality treatment were independent positive prognostic factors for long-term survival $(p<0.05)$. The survival curves of the patients for AST and monocyte are presented in Figure 2-3.

The association between AST, monocytes counts and clinicopathological characteristics. The optimal cutoff point of monocyte count to distinguish the differences of overall survival were determined to be $0.545 \times 10^{9} / \mathrm{L}$ by ROC curves, and $40.0 \mathrm{U} / \mathrm{L}$ was chosen to be a critical value to determine normal or elevated laboratory test of AST. Using these two values, we divided all cases into subgroups to assess the correlation of AST and monocyte count with the clinicopathological characteristics of patients with MPM. There were 94 (89.5\%) 
Table 2. Univariate analysis results of potential prognostic factors of MPM

\begin{tabular}{|c|c|c|c|c|c|c|c|c|c|c|c|}
\hline Variables & $\mathrm{O} / \mathrm{N}^{*}$ & (\%) & $\begin{array}{c}\text { MST }^{\#} \\
\text { (months) }\end{array}$ & $95 \%$ CI & $p$ value & Variables & $\mathrm{O} / \mathrm{N}^{*}$ & (\%) & $\begin{array}{l}\text { MST }^{\#} \\
\text { (months) }\end{array}$ & $95 \%$ CI & $p$ value \\
\hline Age (years) & & & & & 0.456 & r-GGT (U/L) & & & & & 0.149 \\
\hline$\leq 56$ & $29 / 53$ & 54.7 & 22.5 & $18.456-28.944$ & & $\leq 54$ & $31 / 63$ & 49.2 & 23.7 & $15.541-31.859$ & \\
\hline$>56$ & $30 / 52$ & 57.7 & 14.7 & $11.857-23.143$ & & $>54$ & $28 / 42$ & 66.7 & 14.7 & $7.053-22.347$ & \\
\hline Gender & & & & & 0.998 & Neutrophil $\left(\times 10^{9} / \mathrm{L}\right)$ & & & & & 0.075 \\
\hline Male & $36 / 62$ & 58.1 & 21.5 & $16.529-26.471$ & & $\leq 5.89$ & $30 / 65$ & 46.2 & 23.0 & $15.385-30.615$ & \\
\hline Female & $23 / 43$ & 53.5 & 16.5 & $12.825-20.175$ & & $>5.89$ & $29 / 40$ & 72.5 & 16.5 & $6.935-26.065$ & \\
\hline PS & & & & & $<0.001$ & Lymphocyte $\left(\times 10^{9} / \mathrm{L}\right)$ & & & & & 0.136 \\
\hline$<2$ points & $53 / 99$ & 53.5 & 22.5 & $17.164-27.836$ & & $\leq 1.265$ & $20 / 24$ & 83.3 & 13.7 & $0.172-27.228$ & \\
\hline$\geq 2$ points & $6 / 6$ & 100.0 & 1.5 & $0.000-5.305$ & & $>1.265$ & $39 / 81$ & 48.1 & 21.5 & $14.367-28.633$ & \\
\hline Tumor location & & & & & 0.878 & Monocyte $\left(\times 10^{9} / \mathrm{L}\right)$ & & & & & 0.001 \\
\hline Right & $34 / 57$ & 59.6 & 20.0 & $12.781-27.219$ & & $\leq 0.545$ & $20 / 50$ & 40.0 & 33.0 & $13.974-52.026$ & \\
\hline Left & $25 / 48$ & 52.1 & 21.5 & $12.282-30.718$ & & $>0.545$ & $39 / 55$ & 71.9 & 14.7 & $6.789-22.611$ & \\
\hline Anemia & & & & & 0.158 & PLR & & & & & 0.046 \\
\hline Yes & $14 / 19$ & 73.7 & 13.0 & $4.946-21.054$ & & $\leq 155.45$ & $10 / 35$ & 28.6 & 27.0 & $19.690-34.310$ & \\
\hline No & $45 / 86$ & 52.3 & 22.5 & $17.058-27.942$ & & $>155.45$ & $49 / 70$ & 70.0 & 16.5 & $11.315-21.685$ & \\
\hline $\mathrm{RBC}$ & & & & & 0.070 & LMR & & & & & $<0.001$ \\
\hline Normal range & $50 / 93$ & 53.8 & 21.5 & $16.032-26.968$ & & $\leq 2.36$ & $30 / 35$ & 85.7 & 9.5 & $4.708-14.292$ & \\
\hline Below normal & $9 / 12$ & 75.0 & 8.7 & $3.662-13.738$ & & $>2.36$ & $29 / 70$ & 41.4 & 27.0 & $17.781-36.219$ & \\
\hline Pleural effusions & & & & & 0.841 & Treatment strategies & & & & & 0.002 \\
\hline Presence & $51 / 90$ & 56.7 & 19.0 & $12.636-25.364$ & & BSC group & $12 / 15$ & 80.0 & 2.3 & $0.028-4.572$ & \\
\hline Absence & $8 / 15$ & 53.3 & 20.0 & $6.292-33.708$ & & Non-surgical group & $43 / 82$ & 52.4 & 22.5 & $15.347-29.653$ & \\
\hline $\mathrm{WBC}\left(\times 10^{9} / \mathrm{L}\right)$ & & & & & 0.103 & Surgical group & $4 / 8$ & 50.0 & 29.7 & ----- & \\
\hline$\leq 10$ & $44 / 82$ & 53.7 & 21.5 & $15.789-27.211$ & & \multirow{2}{*}{\multicolumn{6}{|c|}{$\begin{array}{l}\text { "Observed death number/total patient number in each group } \\
\text { " median survival time }\end{array}$}} \\
\hline$>10$ & $15 / 23$ & 65.2 & 13.0 & $2.982-23.018$ & & & & & & & \\
\hline Platelet & & & & & 0.996 & & & & & & \\
\hline$\leq 300$ & $23 / 46$ & 50.0 & 23.0 & 13.734-32.266 & & \multirow{12}{*}{\multicolumn{6}{|c|}{$\begin{array}{l}\text { patients with a AST level } \leq 40 \mathrm{U} / \mathrm{L} \text { and } 11(10.5 \%) \text { patients } \\
\text { with a AST level }>40 \mathrm{U} / \mathrm{L} \text {. There were } 50(47.6 \%) \text { patients with } \\
\text { a lower monocyte count }\left(\leq 0.545 \times 10^{9} / \mathrm{L}\right) \text { and } 55(52.4 \%) \text { pa- } \\
\text { tients with a higher monocyte count }\left(>0.545 \times 10^{9} / \mathrm{L}\right) \text {. We found } \\
\text { that higher AST level and monocyte count were both related } \\
\text { to the presence of anemia }(p=0.001 \text { and } 0.010 \text {, respectively) } \\
\text { and higher ALP level }(p=0.049 \text { and } 0.001 \text {, respectively). In ad- } \\
\text { dition, a higher level of AST was also associated with higher } \\
\text { ALT }(p<0.001) \text { and LDH level }(p=0.018) \text {. A higher monocyte } \\
\text { count was also related to male patients }(p=0.010) \text {, higher WBC }\end{array}$}} \\
\hline$>300$ & $36 / 59$ & 61.0 & 18.0 & $11.252-24.748$ & & & & & & & \\
\hline AST (U/L) & & & & & 0.004 & & & & & & \\
\hline$\leq 40$ & $50 / 94$ & 53.2 & 23.0 & $16.956-29.044$ & & & & & & & \\
\hline$>40$ & $9 / 11$ & 81.8 & 10.7 & 7.754-13.646 & & & & & & & \\
\hline $\operatorname{ALT}(\mathrm{U} / \mathrm{L})$ & & & & & 0.695 & & & & & & \\
\hline$\leq 40$ & $41 / 74$ & 53.4 & 22.5 & $15.324-29.676$ & & & & & & & \\
\hline$>40$ & $18 / 31$ & 58.1 & 18.0 & $9.001-26.999$ & & & & & & & \\
\hline $\mathrm{LDH}(\mathrm{U} / \mathrm{L})$ & & & & & 0.016 & & & & & & \\
\hline$\leq 183.5$ & $44 / 85$ & 51.8 & 22.5 & $16.478-28.522$ & & & & & & & \\
\hline$>183.5$ & $15 / 20$ & 75.0 & 13.0 & $5.092-20.908$ & & & & & & & \\
\hline $\operatorname{ALP}(\mathrm{U} / \mathrm{L})$ & & & & & 0.025 & & & & & & \\
\hline$\leq 96.5$ & $24 / 58$ & 41.4 & 29.7 & 13.801-45.599 & & \multirow{3}{*}{\multicolumn{6}{|c|}{ Table 3. Multivariate analysis of risk factors for MPM }} \\
\hline$>96.5$ & $35 / 47$ & 74.5 & 14.7 & $5.762-23.638$ & & & & & & & \\
\hline Serum albumin $(\mathrm{g} / \mathrm{L})$ & & & & & 0.029 & & & & & & \\
\hline$\leq 40$ & $31 / 49$ & 63.3 & 13.7 & $8.515-18.885$ & & \multirow{2}{*}{\multicolumn{3}{|c|}{ Variables }} & \multirow{2}{*}{$\begin{array}{l}\text { Hazard } \\
\text { ratio }\end{array}$} & $95 \% \mathrm{CI}$ & $p$ value \\
\hline$>40$ & $28 / 56$ & 50.0 & 24.0 & $18.147-29.853$ & & & & & & & \\
\hline Globulin $(\mathrm{g} / \mathrm{L})$ & & & & & 0.764 & PS ( $\geq 2$ vs $<2)$ & & & 6.178 & $2.228-17.130$ & $<0.001$ \\
\hline$\leq 35$ & $41 / 76$ & 53.9 & 18.5 & $9.345-27.655$ & & Serum albumin $(\leq 40 \mathrm{v}$ & $s>40)$ & & 1.726 & $0.987-3.018$ & 0.056 \\
\hline$>35$ & $18 / 29$ & 62.1 & 22.5 & $16.184-28.816$ & & AST $(>40$ vs $\leq 40)$ & & & 2.439 & $1.087-5.474$ & 0.031 \\
\hline Glucose & & & & & 0.524 & LDH $(>183.5$ vs $\leq 183.5$ & & & 1.042 & $0.495-2.191$ & 0.915 \\
\hline$\leq 6.1$ & $52 / 88$ & 59.1 & 18.5 & $11.954-25.046$ & & $\operatorname{ALP}(>96.5$ vs $\leq 96.5)$ & & & 1.138 & $0.486-1.591$ & 0.671 \\
\hline$>6.1$ & $7 / 17$ & 41.2 & 23.0 & $13.907-32.093$ & & Monocyte $\left(>0.545 \times 10^{9} /\right.$ & L vs $\leq 0.5$ & $\left.45 \times 10^{9} / \mathrm{L}\right)$ & 2.666 & $1.238-5.738$ & 0.012 \\
\hline Total bilirubin (umol/L) & & & & & 0.105 & PLR $(>155.45$ vs $\leq 155$. & & & 1.695 & $0.760-3.782$ & 0.198 \\
\hline$\leq 19$ & $54 / 98$ & 55.1 & 21.5 & $14.978-28.022$ & & $\operatorname{LMR}(>2.36$ vs $\leq 2.36)$ & & & 1.035 & $0.505-2.121$ & 0.925 \\
\hline$>19$ & $5 / 7$ & 71.4 & 14.0 & $0.000-29.485$ & & Treatment (surgery vs $n$ & on-surge & ry vs BSC) & 0.388 & $0.196-0.769$ & 0.007 \\
\hline
\end{tabular}




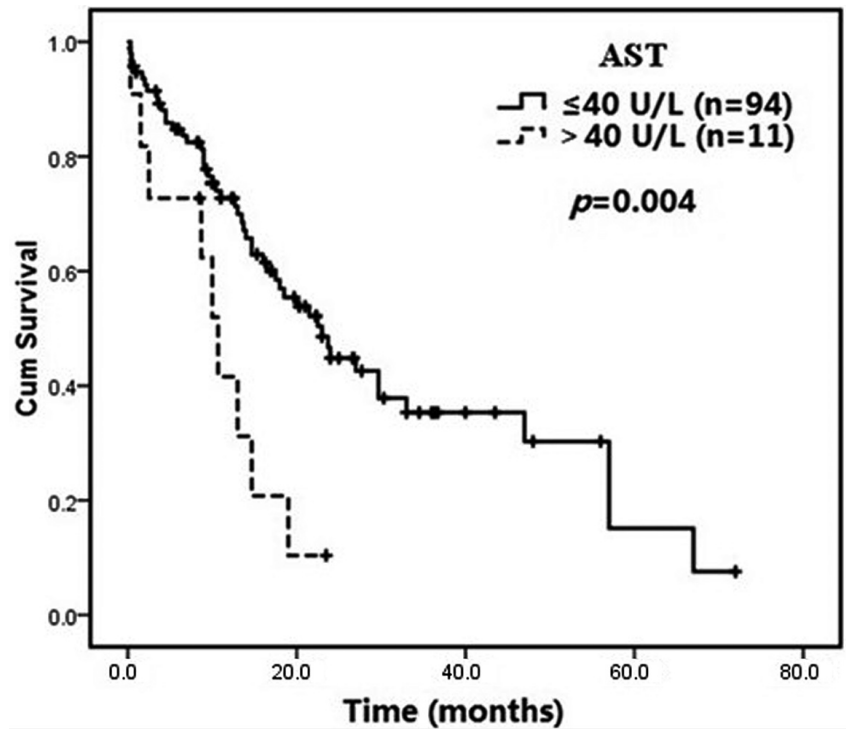

Figure 2. Kaplan-Meier survival curves according to variable AST groups.

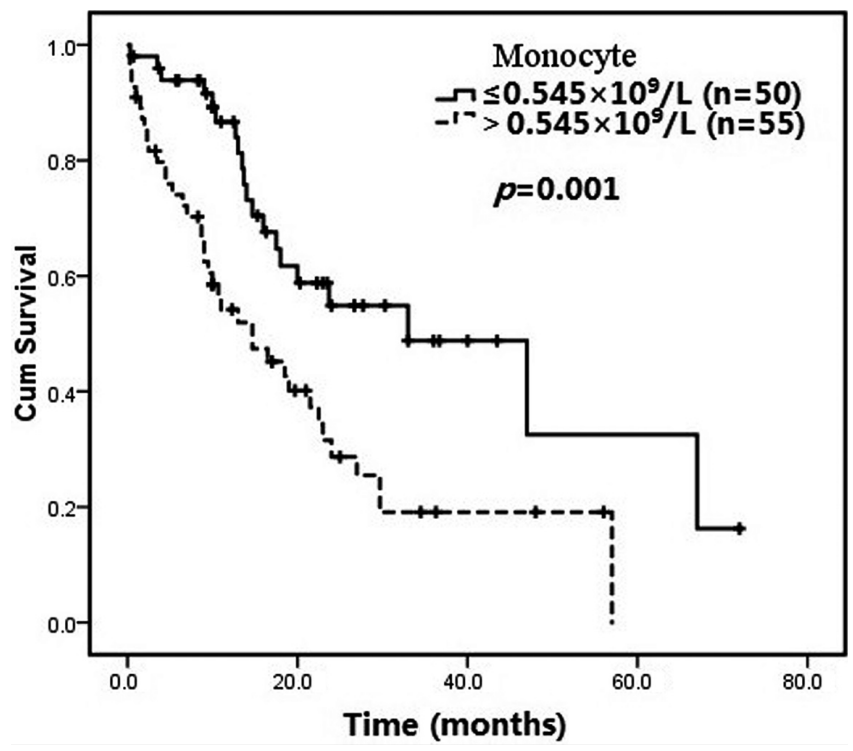

Figure 3. Kaplan-Meier survival curves according to variable monocyte count received by ROC analysis for overall survival (cut off value $=0.545 \times 10^{9} / \mathrm{L}$ ).

$(p<0.001)$, platelet $(p=0.016)$, neutrophil counts $(p<0.001)$, lower RBC $(p=0.023)$ and LMR counts $(p<0.001)$.

Subgroups analysis for overall survival in patients with variable AST levels and monocyte counts. Univariate and multivariate analysis were used to assess the potential prognostic roles of parameters in patients with variable AST levels and monocyte counts. The parameters were the same with Table 4. In higher monocyte count group, significant prognostic factors were PS $(p<0.001)$, AST $(p=0.049), \operatorname{PLR}(p=0.026)$ and treatment strategy $(p=0.022)$ on univariate analysis. Multivariate analysis showed PLR $(p=0.023)$ and treatment strategy $(p=0.005)$ were statistically significant. In lower monocyte count group, age $(p=0.043)$ and PS $(p<0.001)$ were significant prognostic factors on univariate analysis. Only PS $(p=0.008)$ hold statistical significance on multivariate analysis.

In AST $\leq 40 \mathrm{U} / \mathrm{L}$ group, significant prognostic factors included PS $(p=0.004)$, monocyte count $(p=0.004)$, LMR $(p<0.001)$ and treatment strategy $(p=0.002)$ on univariate analysis. Multivariate analysis showed PS $(p=0.002)$, monocyte count $(p=0.040)$ and treatment strategy $(p=0.024)$ were independent prognostic factors. In AST $>40 \mathrm{U} / \mathrm{L}$ group, and PS $(p<0.001), \mathrm{LDH}(p=0.043)$ hold statistical significance on univariate analysis. No statistical significance was found on multivariate analysis. Details can be seen in Table 5 .

\section{Discussion}

MPM is a highly aggressive malignancy and there are currently no uniform therapies for MPM. The identification of prognostic factors plays an important role in prognosis prediction and the management of this fatal disease. In our study, serum biomarkers AST and monocyte were able to independently predict the prognosis of MPM. Additionally, the univariate analysis showed $\mathrm{PS} \geq 2$ points, serum albumin $\leq 40 \mathrm{~g} / \mathrm{L}, \mathrm{AST}>40 \mathrm{U} / \mathrm{L}, \mathrm{LDH}>183.5 \mathrm{U} / \mathrm{L}$, ALP $>96.5 \mathrm{U} / \mathrm{L}$, monocyte $>0.545 \times 10^{9} / \mathrm{L}, \mathrm{PLR}>155.45$, $\mathrm{LMR} \leq 2.36, \mathrm{CEA}>5 \mathrm{ng} / \mathrm{ml}, \mathrm{SCC}>1.5 \mathrm{ng} / \mathrm{ml}$ and best supportive care were correlated with a poor prognosis. The multivariate analysis showed $\mathrm{PS}<2$ points, normal AST range, low monocyte count and multimodality treatment were independent positive prognostic factors of MPM. These results may improve our understanding of the natural history of the disease and are valuable in the management of MPM.

Patient liver function is correlated with treatment options and can be used to monitor treatment responses. Liver function tests are commonly used in clinics. Thus, the identification of liver function parameters to predict the prognosis of MPM patients is valuable. The univariate analysis show that high levels of AST, LDH, ALP and low serum albumin level are risk factors of poor MPM prognosis. However, only AST is statistically significant on multivariate analysis. AST $>40 \mathrm{U} / \mathrm{L}$ is an independent negative prognostic factor for MPM. The AST level is correlated with poor prognosis in multiple myeloma, hepatocellular carcinomas, and colorectal cancer [7-9]. However, its mechanism remains unclear. AST is an important hepatocyte enzyme and will be released into blood when hepatocytes are damaged, which can be useful for the evaluation of liver injury. In addition, serum elevated AST level reveals a higher hepatitis B viral activity in the liver with an decreased overall survival time of hepatocellular carcinoma [24]. High AST level may represents fibrosis and liver inflammatory environment that facilitate the invasion and progression of this lethal disease [25]. A high level of AST 
Table 4. Correlation of the variable AST and monocytes counts with the clinicopathological characteristics of MPM patients

\begin{tabular}{|c|c|c|c|c|c|c|}
\hline \multirow[t]{2}{*}{ Variable } & \multicolumn{3}{|c|}{$\operatorname{AST}(\mathrm{U} / \mathrm{L})$} & \multicolumn{3}{|c|}{ Monocytes $\left(\times 10^{9} / \mathrm{L}\right)$} \\
\hline & $\begin{array}{c}\leq 40 \\
\mathrm{n}(\%)\end{array}$ & $\begin{array}{c}>40 \\
\mathrm{n}(\%)\end{array}$ & $p$ value & $\begin{array}{l}\leq 0.545 \\
\mathrm{n}(\%)\end{array}$ & $\begin{array}{c}>0.545 \\
\mathrm{n}(\%)\end{array}$ & $p$ value \\
\hline Age (years) & & & 0.356 & & & 0.382 \\
\hline$\leq 65$ & $46(48.9)$ & $7(63.6)$ & & $23(46.0)$ & $30(54.6)$ & \\
\hline$>65$ & $48(51.1)$ & $4(36.4)$ & & $27(54.0)$ & $25(45.4)$ & \\
\hline Gender & & & 0.744 & & & 0.010 \\
\hline Male & $55(58.5)$ & $7(63.6)$ & & $23(46.0)$ & $39(70.9)$ & \\
\hline Female & $39(41.5)$ & $4(36.4)$ & ) & $27(54.0)$ & $16(29.1$ & \\
\hline PS & & & 0.060 & & & 0.336 \\
\hline$<2$ points & $90(95.7)$ & $9(81.8)$ & & $46(92.0)$ & $53(96.4)$ & \\
\hline$\geq 2$ points & $4(4.3)$ & $2(18.2)$ & & $4(8.0)$ & $2(3.6)$ & \\
\hline Anemia & & & 0.001 & & & 0.010 \\
\hline Yes & $13(13.8)$ & $6(54.5)$ & & $4(8.0)$ & $15(27.3)$ & \\
\hline No & $81(86.2)$ & $5(45.5)$ & & $46(92.0)$ & $40(72.7)$ & \\
\hline $\mathrm{RBC}$ & & & 0.081 & & & 0.023 \\
\hline Normal & $85(90.4)$ & $8(72.7)$ & & $48(96.0)$ & $45(81.8)$ & \\
\hline Below normal & $9(9.6)$ & $3(27.3)$ & & $2(4.0)$ & $10(18.2)$ & \\
\hline $\mathrm{WBC}\left(\times 10^{9} / \mathrm{L}\right)$ & & & 0.220 & & & $<0.001$ \\
\hline$\leq 10$ & $75(79.8)$ & $7(63.6)$ & & $49(98.0)$ & $33(60.0)$ & \\
\hline$>10$ & $19(20.2)$ & $4(36.4)$ & & $1(2.0)$ & $22(40.0)$ & \\
\hline Platelet & & & 0.243 & & & 0.016 \\
\hline$\leq 300$ & $43(45.7)$ & $3(27.3)$ & & $28(56.0)$ & $18(32.7)$ & \\
\hline$>300$ & $51(54.3)$ & $8(72.7)$ & & $22(44.0)$ & $37(67.3)$ & \\
\hline $\operatorname{ALT}(\mathrm{U} / \mathrm{L})$ & & & $<0.001$ & & & 0.744 \\
\hline$\leq 40$ & $73(77.7)$ & $1(9.1)$ & & $36(72.0)$ & $38(69.1)$ & \\
\hline$>40$ & $21(22.3)$ & $10(90.9)$ & & $14(28.0)$ & $17(30.9)$ & \\
\hline LDH (U/L) & & & 0.018 & & & 0.209 \\
\hline$\leq 183.5$ & $79(84.0)$ & $6(54.5)$ & & $43(86.0)$ & $42(76.4)$ & \\
\hline$>183.5$ & $15(16.0)$ & $5(45.5)$ & & $7(14.0)$ & $13(23.6)$ & \\
\hline $\operatorname{ALP}(\mathrm{U} / \mathrm{L})$ & & & 0.049 & & & 0.001 \\
\hline$\leq 96.5$ & $55(58.5)$ & $3(27.3)$ & $36(72.0)$ & $22(40.0)$ & & \\
\hline$>96.5$ & $39(41.5)$ & $8(72.7)$ & $14(28.0)$ & $33(60.0)$ & & \\
\hline Serum albumin $(\mathrm{g} / \mathrm{L})$ & & & 0.932 & & & 0.896 \\
\hline$\leq 40$ & $44(46.8)$ & $5(45.5)$ & & $23(46.0)$ & $26(47.3)$ & \\
\hline$>40$ & $50(53.2)$ & $6(54.5)$ & & $27(54.0)$ & $29(52.7)$ & \\
\hline Neutrophil $\left(\times 10^{9} / \mathrm{L}\right)$ & & & 0.901 & & & $<0.001$ \\
\hline$\leq 5.89$ & $58(61.7)$ & $7(63.6)$ & & $44(88.0)$ & $21(38.2)$ & \\
\hline$>5.89$ & $36(38.3)$ & $4(36.4)$ & & $6(12.0)$ & $34(61.8)$ & \\
\hline Lymphocyte $\left(\times 10^{9} / \mathrm{L}\right)$ & & & 0.250 & & & 0.111 \\
\hline$\leq 2.095$ & $23(24.5)$ & $1(9.1)$ & & $8(16.0)$ & $21(38.2)$ & \\
\hline$>2.095$ & $71(75.5)$ & $10(90.9)$ & & $42(84.0)$ & $34(61.8)$ & \\
\hline PLR & & & 0.652 & & & 0.167 \\
\hline$\leq 155.45$ & $32(34.0)$ & $3(27.3)$ & & $20(40.0)$ & $15(27.3)$ & \\
\hline$>155.45$ & $62(66.0)$ & $8(72.7)$ & & $30(60.0)$ & $40(72.7)$ & \\
\hline LMR & & & 0.367 & & & $<0.001$ \\
\hline$\leq 2.03$ & $30(31.9)$ & $5(45.5)$ & & $2(4.0)$ & $33(60.0)$ & \\
\hline$>2.03$ & $64(68.1)$ & $6(54.5)$ & & $48(96.0)$ & $22(40.0)$ & \\
\hline
\end{tabular}


Table 5. Significant variables on subgroup analysis

\begin{tabular}{|c|c|c|c|c|c|c|c|c|}
\hline \multirow[t]{2}{*}{ Variable } & \multicolumn{2}{|c|}{$\mathrm{AST} \leq 40 \mathrm{U} / \mathrm{L}$} & \multicolumn{2}{|c|}{$\mathrm{AST}>40 \mathrm{U} / \mathrm{L}$} & \multicolumn{2}{|c|}{ Higher monocytes } & \multicolumn{2}{|c|}{ Lower monocytes } \\
\hline & $\begin{array}{c}\text { MST } \\
\text { (months) }^{*}\end{array}$ & $p$ value & MST & $p$ value & MST & $p$ value & MST & $p$ value \\
\hline PS & & 0.004 & & $<0.001$ & & $<0.001$ & & $<0.001$ \\
\hline$<2$ points & 23.7 & & 13.0 & & 14.7 & & 47.0 & \\
\hline$\geq 2$ points & 3.5 & & 0.3 & & 0.3 & & 3.5 & \\
\hline Monocyte $\left(\times 10^{9} / \mathrm{L}\right)$ & & 0.004 & & 0.515 & & $\varnothing$ & & $\varnothing$ \\
\hline$\leq 0.545$ & 47.0 & & 10.0 & & & & & \\
\hline$>0.545$ & 18.5 & & 10.7 & & & & & \\
\hline LMR & & $<0.001$ & & 0.688 & & 0.114 & & 0.133 \\
\hline$\leq 2.36$ & 9.0 & & 10.7 & & 9.5 & & 3.5 & \\
\hline$>2.36$ & 29.7 & & 10.0 & & 23.0 & & 47.0 & \\
\hline Treatment strategies & & 0.002 & & 0.118 & & 0.022 & & 0.256 \\
\hline BSC group & 2.3 & & 1.5 & & 1.7 & & 33.0 & \\
\hline Non-surgical group & 23.7 & & 10.7 & & 14.7 & & 47.0 & \\
\hline Surgical group & -- & & 19.0 & & 29.7 & & -- & \\
\hline LDH & & 0.189 & & 0.043 & & 0.288 & & 0.055 \\
\hline$\leq 183.5$ & 23.0 & & 13.0 & & 16.5 & & 47.0 & \\
\hline$>183.5$ & 21.5 & & 2.5 & & 11.0 & & 13.0 & \\
\hline AST (U/L) & & $\varnothing$ & & $\varnothing$ & & 0.049 & & 0.120 \\
\hline$\leq 40$ & & & & & 18.5 & & 47.0 & \\
\hline$>40$ & & & & & 10.7 & & 10.0 & \\
\hline PLR & & 0.110 & & 0.310 & & 0.026 & & 0.990 \\
\hline$\leq 155.45$ & 27.0 & & -- & & 27.0 & & -- & \\
\hline$>155.45$ & 18.5 & & 10.0 & & 10.0 & & 33.0 & \\
\hline Age (years) & & 0.515 & & 0.177 & & 0.891 & & 0.043 \\
\hline$\leq 56$ & 24.0 & & 13.0 & & 14.7 & & 47.0 & \\
\hline$>56$ & 18.0 & & 1.5 & & 14.7 & & 17.5 & \\
\hline
\end{tabular}

${ }^{*} \mathrm{MST}=$ median survival time; $\varnothing=$ not assessed on univariate analysis

also extends hospitalizations and delays treatment. We also found AST level was associated with the presence of anemia and ALP, ALT and LDH level $(p<0.05)$. Elevated LDH and ALP levels are also associated with a high tumor burden [10]. Thus, an increased tumor burden may have a role in the poor prognosis.

Chronic inflammation plays a key role in cancer development and progression $[5,13]$. The most common inflammatory markers used for the assessment of prognosis are WBC, platelet count, NLR, and PLR [14-16]. Our results show that decreased monocyte, PLR counts, and increased LMR counts are significant positive prognostic factors of MPM on univariate analysis. High monocyte count is an independent negative prognostic factor of MPM. Tumor-associated macrophages (TAM) are derived from circulating monocytes and are recruited to the tumor microenvironment in cancer patients [17]. Macrophages can be divided into M1 and M2 phenotypes. M1 macrophages are potent effector cells that can kill tumor cells. M2 macrophages are involved in stromal formation, tumor growth, angiogenesis and immunosuppression [18]. Our previous study found in vitro lung cancer cells promote the expression of IL-6 in co-cultures with macrophages and induce epithelial mesenchymal transition (EMT) and invasive ability [19]. The co-culture of macrophages and lung cancer cells induced macrophages to differentiate to the M2 phenotype. Lymphocytes are key anti-tumor cells that inhibit cancer growth and metastasis. Previous studies have shown that increased tumor-infiltrating lymphocyte (TIL) levels are associated with an improved survival in various cancers $[20,21]$. Higher monocyte count was correlated with the presence of anemia, male patients, higher ALP, WBC, platelet, neutrophil counts, lower RBC and LMR counts $(p<0.05)$. A high tumor burden and low immune status can partially account for why high monocytes, PLR counts, and low LMR can contribute to a poorer prognosis.

Rare tumor markers have been suggested in the early detection and diagnosis of MPM. Serum mesothelin-related peptide and osteopontin are two recently discovered serum markers $[11,12]$. Serum mesothelin-related peptide is predictive of disease recurrence. Osteopontin can distinguish between MPM and benign pleural changes. In our study, high CEA and SCC levels were found to be negative prognostic factors of MPM on univariate analysis. However, there was no statistical significance for CA125 and NSE. The samples of patients receive the examination of tumor markers are 
small. Additional studies are required to assess the role of tumor markers, and further investigations are needed for CA125 and NSE due to the elevated levels in more than $40 \%$ of patients.

Subgroups analysis shows that PS has a key role in the prognosis of each group. High PLR count is a poor prognostic factor of the whole series and it holds no statistical significance on multivariate analysis. However, subgroup analysis shows that PLR $>155.45$ is an independent negative prognostic factor of high monocyte count group. PLR plays an important role in the prognosis of high monocyte count group patients. In the same way, monocyte count mainly affects the prognosis of patients in $\mathrm{AST} \leq 40 \mathrm{U} / \mathrm{L}$ group.

In our patient cohort, the 1-, 2- and 5-year survival rates were $68.2 \%, 40.8 \%$ and $13.8 \%$, respectively. These results are better than other published data. The studies performed by Milano MT et al. and Bovolato P et al. showed a 5-year survival rate of $5-12 \%[22,23]$. The patients in our group were registered beginning in April 2007 with a lower median age of 56.0 years. However, other studies involved large patient series treated since the 1980s $[14,22,23]$. It is known that small samples, young age at diagnosis and short intervals may commonly contribute to a better prognosis.

There are limitations of our study. First, this is a small sample retrospective analysis of 105 patients and patient numbers in different treatment groups are not well balanced. Several significant factors such as histologic types, stage at diagnosis, and exposure to asbestos are hardly to be reached and analyzed in detail. Additionally, not all patients were eligible for the assessment of tumor markers. We will pay more attention to these details in our further study. Additional large sample prospective studies are urgently needed to provide evidence-based recommendations for the treatment of this lethal disease.

In conclusion, laboratory examinations of AST, LDH, ALP, monocyte count, PLR and LMR are correlated with MPM prognosis. Our data show that good PS, normal AST level, low monocyte count and multimodality treatment are independent positive prognostic factors of MPM. Elevated AST and monocyte levels represent unfavorable prognostic biomarkers of MPM.

Acknowledgments: This work was supported by National Natural Scientific Foundation of China (No: 81572824 and 81673007).

\section{References}

[1] MOORE AJ, PARKER RJ, WIGGINS J. Malignant mesothelioma. Orphanet J Rare Dis 2008; 3: 34. https:/doi. org/10.1186/1750-1172-3-34

[2] TSAO AS, WISTUBA I, ROTH JA, KINDLER HL. Malignant pleural mesothelioma. J Clin Oncol 2009; 27: 2081-2090. https:/doi.org/10.1200/JCO.2008.19.8523

[3] HAAS AR, STERMAN DH. Malignant pleural mesothelioma: update on treatment options with a focus on novel therapies.
Clin Chest Med 2013; 34: 99-111. https:/doi.org/10.1016/j. ccm.2012.12.005

[4] CARBONE M, LY BH, DODSON RF, PAGANO I, MORRIS PT et al. Malignant mesothelioma: facts, myths, and hypotheses. J Cell Physiol 2012; 227: 44-58. https:/doi.org/10.1002/ jcp. 22724

[5] YAO ZH, TIAN GY, YANG SX, WAN YY, KANG YM et al. Serum albumin as a significant prognostic factor in patients with malignant pleural mesothelioma. Tumour Biol 2014; 35: 6839-6845. https:/doi.org/10.1007/s13277-014-1938-5

[6] CIHAN YB, OZTURK A, MUTLU H. Relationship between prognosis and neutrophil:lymphocyte and platelet:lymphocyte ratios in patients with malignant pleural mesotheliomas. Asian Pac J Cancer Prev 2014; 15: 2061-2067. https:/doi. org/10.7314/APJCP.2014.15.5.2061

[7] KIBA T, ITO T, NAKASHIMA T, OKIKAWA Y, KIDO M et al. Bortezomib and dexamethasone for multiple myeloma: higher AST and LDH levels associated with a worse prognosis on overall survival. BMC Cancer 2014; 14: 462. https:/doi. org/10.1186/1471-2407-14-462

[8] CHANG HC, LIN YM, YEN AM, CHEN SL, WU WY et al. Predictors of long-term survival in hepatocellular carcinomas: a longitudinal follow-up of 108 patients with small tumors. Anticancer Res 2013; 33: 5171-5178.

[9] AHN HJ, OH HS, AHN Y, LEE SJ, KIM HJ et al. Prognostic implications of primary tumor resection in stage IVB colorectal cancer in elderly patients. Ann Coloproctol 2014; 30: 175-181. https:/doi.org/10.3393/ac.2014.30.4.175

[10] WEI XL, ZHANG DS, HE MM, JIN Y, WANG DS et al. The predictive value of alkaline phosphatase and lactate dehydrogenase for overall survival in patients with esophageal squamous cell carcinoma. Tumour Biol 2016; 37: 1879-1887. https:/doi.org/10.1007/s13277-015-3851-y

[11] ROBINSON BW, CREANEY J, LAKE R, NOWAK A, MUSK AW et al. Mesothelin-family proteins and diagnosis of mesothelioma. Lancet 2003; 362: 1612-1616. https:/doi. org/10.1016/S0140-6736(03)14794-0

[12] PASS HI, LOTT D, LONARDO F, HARBUT M, LIU Z, TANG $\mathrm{N}$ et al. Asbestos exposure, pleural mesothelioma, and serum osteopontin levels. N Engl J Med 2005; 353: 1564-73. https:/ doi.org/10.1056/NEJMoa051185

[13] DEL PRETE A, ALLAVENA P, SANTORO G, FUMARULO $\mathrm{R}$, CORSI MM et al. Molecular pathways in cancer-related inflammation. Biochem Med (Zagreb) 2011; 21: 264-275. https:/doi.org/10.11613/BM.2011.036

[14] HERNDON JE, GREEN MR, CHAHINIAN AP, CORSON JM, SUZUKI Y et al. Factors predictive of survival among 337 patients with mesothelioma treated between 1984 and 1994 by the Cancer and Leukemia Group B. Chest 1998; 113: 723-731. https:/doi.org/10.1378/chest.113.3.723

[15] CURRAN D, SAHMOUD T, THERASSE P, VAN MEERBEECK J, POSTMUS PE et al. Prognostic factors in patients with pleural mesothelioma: the European Organization for Research and Treatment of Cancer experience. J Clin Oncol 1998; 16: 145-152.

[16] WU G, YAO Y, BAI C, ZENG J, SHI D et al. Combination of platelet to lymphocyte ratio and neutrophil to lymphocyte 
ratio is a useful prognostic factor in advanced non-small cell lung cancer patients. Thorac Cancer 2015; 6: 275-287. https:/ doi.org/10.1111/1759-7714.12178

[17] MANTOVANI A, SCHIOPPA T, PORTA C, ALLAVENA P, SICA A. Role of tumor associated macrophages in tumor progression and invasion. Cancer Metastasis Rev 2006; 25: 315-322. https:/doi.org/10.1007/s10555-006-9001-7

[18] MANTOVANI A, SICA A, SOZZANI S, ALLAVENA P, VECCHI A et al. The chemokine system in diverse forms of macrophage activation and polarization. Trends Immunol 2004; 25: 677-686. https:/doi.org/10.1016/j.it.2004.09.015

[19] DEHAI C, BO P, QIANG T, LIHUA S, FANG L et al. Enhanced invasion of lung adenocarcinoma cells after co-culture with THP-1-derived macrophages via the induction of EMT by IL-6. Immunol Lett 2014; 160: 1-10. https:/doi.org/10.1016/j. imlet.2014.03.004

[20] HORNE ZD, JACK R, GRAY ZT, SIEGFRIED JM, WILSON $\mathrm{DO}$ et al. Increased levels of tumor-infiltrating lymphocytes are associated with improved recurrence-free survival in stage 1A non-small cell lung cancer. J Surg Res 2011; 171: 1-5. https:/doi.org/10.1016/j.jss.2011.03.068

[21] HALAMA N, MICHEL S, KLOOR M, ZOERNIG I, BENNER A et al. Localization and density of immune cells in the inva- sive margin of human colorectal cancer liver metastases are prognostic for response to chemotherapy. Cancer Res 2011; 71: 5670-5677. https:/doi.org/10.1158/0008-5472.CAN-11$\underline{0268}$

[22] BOVOLATO P, CASADIO C, BILLÈ A, ARDISSONE F, SANTAMBROGIO L et al. Does surgery improve survival of patients with malignant pleural mesothelioma?: a multicenter retrospective analysis of 1365 consecutive patients. J Thorac Oncol 2014; 9: 390-396. https:/doi.org/10.1097/ LTO.0000000000000064

[23] MILANO MT, ZHANG H. Malignant pleural mesothelioma: a population-based study of survival. J Thorac Oncol 2010; 5: 1841-1848. https:/doi.org/10.1097/JTO.0b013e3181f1cf2b

[24] WITJES CD, IJZERMANS JN, VAN DER EIJK AA, HANSEN BE, VERHOEF C et al. Quantitative HBV DNA and AST are strong predictors for survival after HCC detection in chronic HBV patients. Neth J Med 2011; 69: 508-513.

[25] CICHOZ-LACH H, CELINSKI K, PROZOROW-KROL $B$, SWATEK J, SLOMKA $M$ et al. The BARD score and the NAFLD fibrosis score in the assessment of advanced liver fibrosis in nonalcoholic fatty liver disease. Med Sci Monit 2012; 18: CR735-740. https:/doi.org/10.12659/ $\underline{\text { MSM.883601 }}$ 